\title{
Correction: Trends in intensive neonatal care during the COVID-19 outbreak in Japan
}

Maeda Y, Nakamura M, Ninomiya $\mathrm{H}$, et al. Trends in intensive neonatal care during the COVID-19 outbreak in Japan. Arch Dis Child Fetal Neonatal Ed 2021;106:327-29. doi: 10.1136/archdischild-2020-320521

The authors have noticed an error in table 1 of their short report recently published. They mistakenly showed values for weeks $10-17$ of 2019 instead of those for weeks 2-9 of 2020 . The values for 'Births before 33 6/7 weeks' and 'Births between 34 0/7 and 36 6/7 weeks' of Table 1 should be amended as follows:

Births before 33 6/7 weeks

Weeks 2-9, 2020: 83, instead of 99

Difference (\% change): 17 (20.5), instead of 33 (33.3)

Births between $340 / 7$ and 36 6/7 weeks

Weeks 2-9, 2020: 207, instead of 211

Difference (\% change): 17 (8.2), instead of 21 (10.0)

Accordingly, the second sentence of the subsection 'Preterm births' should also be corrected to "The number of preterm births showed a statistically significant reduction in weeks 2-9 vs weeks 10-17 of 2020: births before 33 6/7 gestational weeks from 83 to 66 (aIRR, 0.71; $95 \% \mathrm{CI}, 0.50$ to $1.00 ; \mathrm{p}=0.05$ ) and births between $340 / 7$ and $366 / 7$ gestational weeks from 207 to 190 (aIRR, 0.85 ; 95\% CI, 0.74 to $0.98 ; \mathrm{p}=0.02$ ) (figure 1 and table 1 ).

(C) Author(s) (or their employer(s)) 2021. No commercial re-use. See rights and permissions. Published by BMJ.

Arch Dis Child Fetal Neonatal Ed 2021;106:e3. doi:10.1136/archdischild-2020-320521corr1

D) Check for updates 